\title{
Sociological Study of Mental Disorders in HCMC (Vietnam)
}

\author{
Mohamad Tavakol${ }^{1}$, Le Thi Mai², Mina Mansouri ${ }^{3}$ \\ ${ }^{1}$ Professor of Sociology, University of Tehran, Tehran, Iran \\ ${ }^{2}$ Head of Sociology Department, TDT University, HCMC, Vietnam \\ ${ }^{3}$ M.A. holder in Sociology, Tehran, Iran \\ mtavakol@ut.ac.ir, lethimai@tdtu.edu.vn,mina.mansouri@gmx.com
}

\begin{abstract}
The focus of this study is on the prevalence of mental disorders among the people aged between 18-64 years who are living in Saigon (HCMC), and an analysis of the sociological factors that affect the spread of these disorders. The theoretical framework of this research is a synthesis of the sociological theory of Anomie of Durkheim and the Strain theory of Merton. To determine the prevalence of mental disorders, the General Health Questionnaire (GHQ-28) is used, and to determine their effective sociological parameters we prepared a second Questionnaire, the sociological one, comprising questions derived from Durkheim and Merton's theories. The sample size was 384, using Cochran formula, and sampling was a multi-stage cluster sampling. The results from the analyses of the data showed that the overall prevalence of mental disorder in Saigon is $10.2 \%$ : in men $5.5 \%$ and in women $12.8 \%$. Moreover, the components of immigration, job status, social status, structural and social pressures, family problems, and social capital, were shown to contribute to the risk of mental health and the occurrence of mental disorders. The sociological factors which were not confirmed were religion and ethnicity.
\end{abstract}

Keywords: Mental health; Medical Sociology; Mental disorder; Saigon/HCMC; Sociological parameters

\section{Introduction}

Health is defined as "a state of complete physical, mental, and social well-being and not merely the absence of disease or infirmity" by the World Health Organization (WHO, 2018). In general, the three dimensions of physical, mental, and social well-being, while seemingly unrelated, are in interaction continuously. "Mental health is as important as physical health to the overall well-being of individuals, societies and countries. Yet, only a small minority of the 450 million people suffering from a mental or behavioral disorder is receiving treatment. Advances in neuroscience and behavioral medicine have shown that, like many physical illnesses, mental and behavioral disorders are the result of a complex interaction between biological, psychological and social factors" (WHO, 2008). The high rates of mental disorders in developed and developing countries as well as the consequent economic and social costs are heavy. On the other hand, the negative effects on the afflicted individuals and their family include suicide, divorce, drug and alcohol abuse, unemployment, violence, and a damaged social life. Considering all these, a mental disorder can be counted a very serious social issue.

As a matter of fact, the amount of research on mental disorders worldwide is huge and until quite recently, mainly in the frameworks of psychology, behavioral therapy, biology, and criminology. But it is the attention towards the effective social factors in mental disorders that sets the orientation of this study. More and more researchers have come to understand the major share of social realities in shaping, spreading, and treating these disorders and the move towards an interdisciplinary approach in the field has been a meaningful turn towards sociology and its offshoots such as medical sociology. Aneshensel and Flen, for example, try to explain the way a society can contribute to the mental well-being of its members and moreover, the life of those regarded as individuals with mental disorders, focusing on "how society shapes the thoughts, feelings, and actions of its members in ways that are considered to be mental illness, and with the consequences of having, or being thought to have, a mental illness" (Aneshensel et al., 2012). Similarly, Cockerham points to the fact that "with increasing numbers of studies uncovering a significant relationship between social factors and many psychiatric conditions, the study of mentally disturbed behavior has become an important area of research in sociology" (Cockerham, 2017).

As a great development, nowadays talk about the "social determinants of mental health" is more widespread in academic and policy-making circles (Allen et al., 2014, Sederer, 2016, Carod-Artal, 2017). The importance of social factors, compared to the ever-present biological and psychological factors in mental 
disorder, is less recognized in developing countries. As a matter of fact, in these countries, due to the heavier economic and social problems and their effects on mental disorders, though the statistics are rising officially and unofficially, the information is not comprehensive, coherent, and consistent. Also the studies conducted are normally in most cases narrow in their scope, and not multidisciplinary/interdisciplinary, and mainly focus on either biological or psychological factors. Clearly it is impossible to improve mental health situation without accurate data about the prevalence and etiology of a problem. Obviously wrong or deficient information about this issue can lead to a misunderstanding about the critical condition and this, naturally, results in sometimes unrelated decisions to face the problem (Shim and Compton, 2018). A similar unfavorable research situation regarding the mental health issue applies to Vietnam as well. The Socialist Republic of Vietnam, with a population exceeding 95 million in 331 square kilometres located in South Eastern Asia, is the 14th most populated country on the planet. In less than half a century, Vietnam has gone through three wars: the war with the Japanese, the French, and the Americans. The Vietnam War, the worst war after World War 2, resulted in the American defeat and their retreat in 1975. Vietnam, which was nothing but the rubble after the war, started a reconstruction program and since 2000, its economic growth is among the highest in the world (ADB, 2018). Its adamant pursuit of economic liberalization policy has led to Vietnam's rapid industrialization. This country is among the few nations which have had the lowest unemployment rates for several consecutive years. The following chart presents an overall view of the unemployment in Vietnam:

Figure 1: Overview of Unemployment

VIETNAM UNEMPLOYMENT RATE

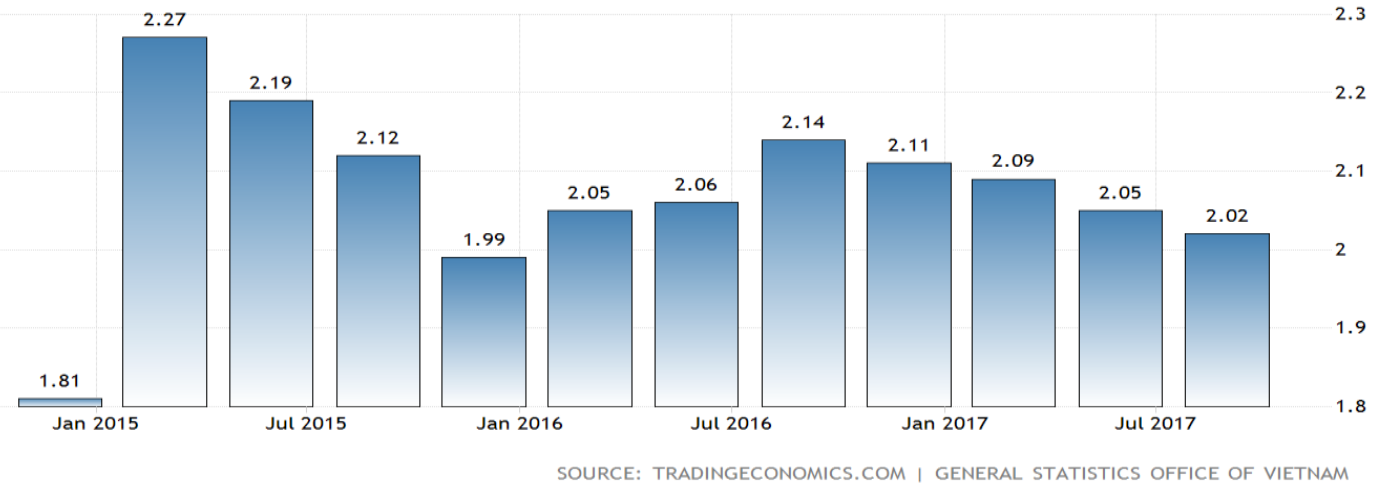

\section{Literature Review}

The reason for the attention to mental disorder, apart from its being a pandemic, is its high cost of control and, in some cases, of treatment, as well as its heavy social, economic, and cultural impacts. Therefore, prevention is the best and cheapest approach to this problem. As mentioned earlier, the growing rates of mental disorders, especially in less developed countries such as Vietnam, show the urgent need to pay more attention to this problem. Most of the studies conducted in developed countries are applied, for special purposes, and planned for certain time intervals. In contrast, in the developing countries, such epidemiological studies on mental disorders are not very old and they mostly, except for a limited number of large-scale studies on the prevalence of mental disorders, are rather in the form of descriptive reports and are not scientific research. In the following paragraphs, first we have an overview of some of the global and local papers addressing mental health and mental disorders. In an article entitled "Social determinants of mental health: a review of the evidence", Manuela Silva, Adriana Loureiro, and Graça Cardoso's aim is to present a non-systematic narrative review of the published evidence on the association between mental health and socio-demographic and economic factors at individual-and at area-level. The results were: out of 150 studies (carried out between 2004 and 2014), 78 assessed associations between individual-level factors and mental health. The main individual factors which had significant relation with worse mental health were low income, not living with a partner, lack of social support, female gender low level of education, low income, low socioeconomic status, unemployment, financial strain, and perceived discrimination. 
The Chart Below Shows the Data for Unemployment, Income, Population Rates and Other Sociological and Economic Factors:

\begin{tabular}{|c|c|c|c|c|c|}
\hline Vietnam Labour & Last & Previous & Highest & Lowest & Unit \\
\hline Unemployment Rate & 2.02 & 2.05 & 4.50 & 1.63 & percent \\
\hline Employed Persons & 53.76 & 53.40 & 53.76 & 23.50 & Million \\
\hline Unemployed Persons & 1.11 & 1.12 & 2.30 & 0.80 & Million \\
\hline \multirow[t]{2}{*}{ Minimum Wages } & 3980.00 & 3750.00 & 3980.00 & 1000.00 & VND \\
\hline & & & & & Thousand/Month \\
\hline Population & 92.70 & 91.70 & 92.70 & 34.74 & Million \\
\hline Retirement Age Men & 60.00 & 60.00 & 60.00 & 60.00 & \\
\hline Retirement Age Women & 55.00 & 55.00 & 55.00 & 55.00 & \\
\hline \multirow[t]{2}{*}{ Wages } & 5364.00 & 5202.00 & 5507.00 & 1399.00 & VND \\
\hline & & & & & Thousand/Month \\
\hline Wages High Skilled & 11409900.00 & 12286900.00 & 12286900.00 & 10241600.00 & VND/Month \\
\hline \multirow[t]{2}{*}{ Wages In Manufacturing } & 5463.00 & 5122.00 & 5463.00 & 2871.00 & VND \\
\hline & & & & & Thousand/Month \\
\hline Wages Low Skilled & 4851300.00 & 5498500.00 & 7386200.00 & 4851300.00 & VND/Month \\
\hline Youth Unemployment Rate & 7.80 & 7.67 & 7.86 & 5.17 & percent \\
\hline $\begin{array}{l}\text { Labor Force Participation } \\
\text { Rate }\end{array}$ & 76.70 & 76.40 & 77.50 & 76.40 & percent \\
\hline Living Wage Family & 7475300.00 & 7475300.00 & 7475300.00 & 7475300.00 & VND/Month \\
\hline Living Wage Individual & 4131400.00 & 4131400.00 & 4131400.00 & 4131400.00 & VND/Month \\
\hline
\end{tabular}

Though there are good statistics on some important aspects of Vietnamese life, the prevalence of mental disorder in Vietnam is totally vague. "In Vietnam, Mental disorders have not been adequately researched. A national representative epidemiological survey on 10 most common mental disorders combined had a prevalence of approximately $14.9 \%$ of the population. Estimating from this result about 12 million people are in need of MHS [Managed Health Services]. The most prevalent of these are alcohol abuse (5.3\%), depression (2.8\%) and anxiety (2.6\%)" (Vuong et al., 2011: 66; Nguyen, 2018). According to a report in 2016, the Ministry of Labour, Invalids and Social Affairs estimated that 15 percent of Vietnam's population suffers from one of ten common disorders. The report also informs that 20 percent of 8-17 years old children suffer from such problems. It adds that only 20-30 percent of the patients receive treatment-usually medically rather than psychologically (VnExpress, 2016). The disregard for mental disorders and mental health, and the effective social factors in particular, is rather a global fact. Almost 2 decades ago, WHO issued a serious warning regarding this harmful neglect and pointed to the important effects of socio-psychological factors on health which is estimated to be about 85\%. HCMC is the biggest industrial city in Vietnam with a big diversity of jobs and professions, immigrations, ethnicities and religions, socio-economic strata, and subcultures. In this research, we aimed to show the current state of mental disorder in our sample population in HCMC and 
examine its effective sociological factors which contribute to the situation. 69 studies confirmed the relationship between area-level factors and mental health, namely neighborhood socioeconomic conditions, social capital, geographical distribution and built environment, neighborhood problems and ethnic composition (Silva et al., 2016). In a study carried out in Holland and titled "A Meta-Analysis of the Relation Between Mental Disorders and Crime Recurrence", Wibblenik conducted a three-level meta-analysis of 20 texts (17 independent studies, $\mathrm{N}=5737$ ) focusing on internalization, externalization, and combined (a combination of an internal and an external disorders) disorders.

The findings indicate that "type of delinquency (e.g., overt and covert delinquency), and gender influenced the direction and magnitude of the associations between recidivism and internalizing and externalizing disorders." (Wibbelink et al., 2017: 78). Also, Kugelmass and Garcia, in a study titled "Mental Disorders among the Secular American Youth" reached at three major outcomes: "First, nonreligious adolescents on average have higher rates of mental disorder than adolescents who identify as religious. Second, there is variability in rates of mental disorder among the three types of nonreligious adolescents, with atheists/agnostics experiencing the highest rates, followed by those with no religion, and those with no religious preference. Indeed, after controlling for a host of socio-demographic characteristics, adolescents with no preference have levels of mental disorder that do not defer from the religiously affiliated. Third, the mental health disadvantage of no religiosity is strongest among nonreligious adolescents with two highly religious parents. Their rates of mental illness are almost twice that of religious adolescents raised in religious households. Moreover, neither nonreligious nor religious adolescents are negatively affected by being raised in nonreligious households" (Kugelmass and Garcia, 2015: 368). Das and colleagues in their paper Mental health patterns and consequences: Results from survey data in five developing countries" stress that though the social and economic consequences of poor mental health in the developing world are presumed to be significant, they remain under-researched. This study uses data from nationally representative surveys in Bosnia and Herzegovina, Indonesia, and Mexico as well as India and Tonga to confirm the similar relationships between mental health and socioeconomic feature.

The elderly, females, the widowed, and those who report poor physical health are more likely to report worse mental health. Individuals living with others with poor mental health are also significantly more likely to report worse mental health themselves, the paper says. In contrast, the paper claims that there is a littleobserved relation between mental health and consumption poverty or education, two common measures of socioeconomic status. It is rather suggested instead that economic and multidimensional shocks, such as illness or crisis, can have a greater impact on mental health than poverty. This may have important implications for social protection policy. It is interesting that though the authors are the World Bank economists their research gives prominence to social factors affecting mental health (Das et al., 2009). Concerning Vietnam, Richardson and others published a paper titled "Estimating mental distress in Vietnam: The use of SRQ-20" in which they used SRQ-20 on a population of 5000 and reached the number $19.2 \%$ as the probable percentage of Vietnamese people with mental disorder. They mention that "our estimate of mental distress using the SRQ-20 is much greater than that of other studies, and in contrast to western prevalence studies, age was not a protective factor in this study." (Richardson et al., 2010: 133). Huy et al. have carried out fieldwork research in Hanoi which is reported in the paper "Factors Associated with Depression among Male Casual Laborers in Urban Vietnam". This study is concentrated on the level, the prevalence, and the factors affecting depression among male casual laborers in Hanoi. Sampling consisted of 450 men most were from the rural and mountainous provinces. The prevalence of self-reported depressive symptoms, $25 \%$, was high. Structural equation modelling had been used in the research. It was shown that marriage, family separation and living with peers or partners were three significant distal risk factors, while illicit drug use and low social connectedness were proximal predictors of depression. Of all factors, it is argued that social connectedness appeared to be the most important because it plays a mediating role, and drug use was an independent risk factor (Huy et al., 2015).

In another study mentioned earlier, Vuang describes different kinds of mental disorders in Vietnam and concludes that although there has been a growth and improvements in services provided for mental patients, they are by no means sufficient for their large numbers. There is an urgent need for a variety of specialized services, medical staff training, and epidemiological and interceptive studies. A more recent study, "Political Economy and Mental Health in Vietnam", by Kelly Lee and associates, begins with the narrating from a report 
by WHO in 2003; $13 \%$ of illnesses worldwide are mental disorders and three-quarters of which happen in countries with low or medium income. Moreover, countries engaged in a political and economic transition period are in deeper trouble. Finally, focusing on the effects of the political economy in Vietnam on mental disorders, it concludes that the globalization and transition process can act both as a threat and an opportunity in relation to mental health services (Lee et al., 2015). In the paper "Early life shocks and mental health: The long-term effect of war in Vietnam", Sing Hal aims to show the causal relationship between earlylife exposure to war and mental health in adulthood. Using an instrumental variable strategy, the evidence confirms that early-life exposure to bombing during the American war in Vietnam had long-term effects. The paper explains that a one percent increase in bombing intensity during 1965-75 increased the likelihood of severe mental distress in adulthood by 16 percentage points.

Theoretical Framework: As mentioned before, mental health is vulnerable from structural factors which go beyond the individual. One of the most important statements about the effect of social and structural factors on the mental health of individuals belongs to Emile Durkheim. He is among the top theorists who have discussed the problems of modern society from a structural point of view. As evidence in one of his seminal studies, Suicide, Durkheim has analyzed extensively the social structural factors that encourage a person, mentally, to take his own life. In this book, Durkheim explained that biological concepts (and also merely psychological ones) cannot entirely explain human behavior. Durkheim described that although suicide is apparently an individual and personal phenomenon, this anomic phenomenon cannot be considered as an entirely personal decision which is made under the influence of personal difficulties or mental problems. There are hidden forces which lead the individual to commit suicide. There are many studies which followed Durkheim's line of thought. Economic crisis such as downturn and inflation, bankruptcy, extended unemployment, have different consequences in the social life of individuals and consequently, the harmful effects of these crises on individuals' mental health are considerable. Durkheim in his Suicide claimed that economic fluctuations and suicide rates are related and during downturns, committing suicide is high. He explains that this phenomenon cannot be merely the consequence of poverty because the suicide rate among those who have always been poor is the lowest. In addition, the increase in suicide is not only in the periods of the downturn but also it does increase in the periods of economic boom. Therefore, the main factor is not the economic condition as such but the inconsistency that it brings to our social life.

During the crisis, the usual moral principles which affect the individual's social functions undergo pressure and lose control (Giddens, 1997). Durkheim's anomie theory has the explanatory potential to make mental illness understood. After analyzing the suicide rates in different industrial and non-industrial countries and then comparing them with each other, Durkheim concludes that the anomic division of labor in industrialized societies will lead to social collapse unless exists an integrative moral basis and a minimum of collective conscience (Durkheim, 2005). In a sense, his comprehensive study on this anomic situation analyzes the effects of macro scale and structural components on mental disorder and health. Among the sociologists who have been influenced by Durkheim and advanced his views, Robert Merton is one of the most prominent. In his works in medical sociology, Merton considers social etiology and ecology of diseases, including mental disorders, to be a very important part (Tavakol \& Armstrong, 2013). Merton's strain theory, which is sometimes referred to as a means-ends theory, or Merton's anomie theory, is a more concrete interpretation, and a clarification of Durkheim's anomie which is more transparent and applicable within his middle range theoretical framework (Merton, 1938). Our approach to social aspects of mental disorder in this research has been Mertonian in this sense. According to Merton's Structural-Functional Sociology, society is like a system made up of a group of structural components such as cultural and social structures. Cultural and social structures interact with each other to make the continuity of the social system and its coordination with the people and environment: "If the social structure restrains some dispositions to act, it creates others. The functional approach therefore abandons the position, held by various individualistic theories, that different rates of deviant behaviour in diverse groups and social strata are the accidental results of varying proportions of pathological personalities found in these groups and strata.

It attempts instead to determine how the social and cultural structure generates pressure socially deviant behavior upon people variously located in that structure (Merton, 1968: 175-176). Following Durkheim's footsteps, Merton believes that the continuity of anomic conditions can have various consequences for the mind of the individual but unlike Durkheim, he does not see it as an outcome of a sudden change but he 
believes it to be the result of the problems within the existing social structure. Such a situation, Merton maintains, is the result of the unreachable gap between the accepted social goals and the legitimate means of attaining them in the society. This means that society encourages individuals to achieve certain goals while the means for attaining such goals are out of reach. In a sense, some individuals are forced to either choose specific goals reachable to them or use illegitimate means to reach those goals which their culture has allowed them to consider (Merton, 1995). Under such conditions, the individual goes through frustration and other diverse pressures which may lead to an outbreak of mental disorder. Although it is true that Merton proposed the strain theory to explain deviations, it is and will be an effective framework for understanding mental disorders too. Merton's understanding of anomie is a state of confusion which results in the anarchy of social value system. The direct impact of such anarchy is certain anxieties from which many people suffer. Merton's explanation of anomie is related to mental disorder in two ways. First, negative conditions such as confusion and anarchy can lead people to mental disorders. Second, the lack of balance between the expectations and real achievements will affect the mental health.

The individual negatively (Aseltine, 2000, Bessa, 2012: 35), the effects of social inequalities, for example, on mental disorders have been confirmed also by more recent studies (Fryers, 2003). The social parameters which can act as strains against mental health are inserted in our sociological questionnaire, as a complement to more psychological questionnaire GHQ-28. The paper describes that negative effects of war are similar for both men and women (Singhal, 2018). Nguyen, Hoi Van , Ha ThiHai Do, Van ThiAnh Le \& Ngoc-Anh Mai in their paper entitled "Reviewing the latest national policies and services for people with severe mental health disorders in government-funded institutions in Vietnam, and policy recommendations for service improvements" admit the deficiencies and shortcomings in mental health matters, and after reviewing the works and specifically the related policies in Vietnam come up with some recommendations to improve the situation (Hoi Van Nguyen et al., 2018).

Research Hypotheses: Within the aforementioned Mertonian theoretical framework, in order to see the effective social factors on major mental disorders such as depression, schizophrenia, emotional disorders, panic attacks, general anxiety disorder, and OCD, we formulated the research hypotheses as follows:

- Education is related to the prevalence of mental disorders

- Employment is related to the prevalence of mental disorders

- Socio-economic status is related to the prevalence of mental disorders.

- Gender is related to mental disorder rates.

- Ethnicity is related to the prevalence of mental disorders.

- Migration is related to the prevalence of mental disorders

- Urban life problems (social strain, social descent, lack of social support and sympathy and trust, fluctuation of social capital, etc.) increase mental disorders.

- Religiosity is related to the prevalence of mental disorders.

\section{Methodology}

In this study we aimed at getting an estimate of the mentally disordered people in HCMC and to analyses the social factors affecting mental health or disorder. Along with using national data, research reports on health and mental disorder, and other secondary sources, interviews with psychologists, and psychoanalysts, fresh data was gathered quantitatively, using 2 previously mentioned questionnaires. In this analytic-descriptive study, the prevalence of mental disorders was measured among HCMC citizens aged from 18 to 64. Using probabilistic and multi-stage cluster sampling, and based on the city maps, different social class districts were identified (D1 \& D3 upper class, D5 almost upper class, Binh Tan middle class, D8 lower class, and Riverside very low class), and then blocks and neighborhoods were chosen to distribute and complete the questionnaires. Then, data was gathered using simple or systematic random sampling. The sample population was 384 according to Cochran formula. Morgan's chart showed the same number, 384, as well. General Health Questionnaire (GHQ-28) was used to measure the prevalence and the types of mental disorders. The questionnaire was first translated from English into Vietnamese and after the pretest they were answered in the aforementioned districts. As explained in the theoretical section, the questions concerning the effective 
sociological parameters on mental disorders were put into a separate questionnaire consisting of 19 questions (Sociological Questionnaire) which were also answered by the sample population. The GHQ-28 questions were answered using Likert's four-point scale: "No", "a little", "a lot", "too much". Higher scores were given to those answers that showed the signs of mental disorder.

This scale was also pre-tested in clusters of 30 individuals and then underwent analyses to measure the internal compatibility of each question with the total scale score. To determine the possibility of subscales, the scale was post-tested using factor analysis. Regarding the Sociological Questionnaire, parameters such as anomie, social pressure, social capital fluctuations, employment status, class and socio-economic status, educational level, migration, religiosity, etc. were measured using a dual spectrum of yes or no. This meant that the preference for an option meant having the attribute and not choosing it was taken for its lacking. Finally, data analysis was completed by entering the data into SPSS, and a descriptive and inferential analysis was provided for explaining the relations between the variables. For analyzing each hypothesis, based on the gathered data, the appropriate statistical method was employed. For example, the concept of religiosity was measured in 5 items. For analyzing this variable, the code 1 (meaning yes) was assigned to those respondents who had given a positive answer and the code 0 for those doing the opposite.

Linear regression was used since the dependent variable here (mental disorder) was measured by the interval scale, and it was assumed that here there was a causal relationship between the dependent and independent variables. In some cases, in order to evaluate the direct effect of independent variables on dependent variables the aforementioned distance scale was replaced by the nominal scale (individuals suffering from mental disorders and individuals without mental disorders). Factor analysis also was used in order to evaluate the subtest validity. GHQ-28 consists of 4 sub-tests each of which has 7 equivalent questions that evaluate one aspect of mental health. Therefore, each aspect of the mental health questionnaire should be correlated with only one common factor. In the following table, we observe the validity and reliability of GHQ-28.

Table 1: Results

\begin{tabular}{|c|c|c|c|c|c|c|}
\hline \multirow[t]{2}{*}{ Aspects } & \multirow[t]{2}{*}{ Factor } & \multicolumn{3}{|c|}{ Total Variance } & \multirow[t]{2}{*}{ KMO } & \multirow{2}{*}{$\begin{array}{l}\text { Bartlett's } \\
\text { Test for } \\
\text { Sphericity }\end{array}$} \\
\hline & & $\begin{array}{l}\text { Special } \\
\text { Amount }\end{array}$ & $\begin{array}{l}\text { Variance } \\
\text { Percentage }\end{array}$ & $\begin{array}{l}\text { Cumulative } \\
\text { Percentage }\end{array}$ & & \\
\hline \multirow[t]{2}{*}{ Physical Signs } & 1 & 201.4 & 60 & 60 & 0.902 & $000 / 0$ \\
\hline & 2 & 0.696 & 94.9 & 70 & & \\
\hline \multirow[t]{2}{*}{ Anxiety } & 1 & 26.3 & 46.6 & 44.6 & 0.795 & $000 / 0$ \\
\hline & 2 & 0.971 & 13.8 & 60.5 & & \\
\hline Disrupted & 1 & 3.81 & 55.54 & 54.5 & 0.865 & $000 / 0$ \\
\hline Function & 2 & 0.98 & 14 & 68.6 & & \\
\hline Depression & 1 & 4.11 & 55.8 & 55.8 & 0.883 & $000 / 0$ \\
\hline Symptoms & 2 & 0.903 & 12.9 & 71.7 & & \\
\hline
\end{tabular}

The findings of the table also suggest that all of the 4 aspects of mental health have only 1 factor or equivalent special amount larger than 1 . As a result, the number of final factors for each aspect of mental health is only one factor which shows that the mental health subtest questions are equivalent. KMO indicator, which shows the correlation of variables, was used to find the proper variables for factor analysis. This indicator ranges between 0 and 1 . The larger amounts mean that the variables are better for the factor analysis. Findings of the table show that all amounts of KMO indicator are between 0.8 and 0.9 which means that the variables correlation is fit for the factor analysis. On the other hand, regarding the Bartlett Test results, the factor analysis results are generalizable to the total population. The GHQ-28 reliability was evaluated by Cronbach's Alpha which was 0.934 for the entire questionnaire, 0.882 for physical signs factor, 0.803 for anxiety factor, 0.847 for a disrupted social function, and 0.879 for depression symptoms. This means that the questions are highly compatible. The results of the KMO indicator and Bartlett's Test, regarding other questions and subfactors of the study, show the results to be generalizable and the questions to be highly compatible with one another. 


\section{Findings}

Using the standard GHQ-28, the prevalence of mental disorder in the research population in Saigon was $10.2 \%$. The gender-based amount is $5.5 \%$ for males and $12.8 \%$ for females. The following tables show some of the extracted data:

Table 2

\begin{tabular}{lllll}
\hline $\begin{array}{l}\text { Descriptive statistics of } \\
\text { the respondents' age }\end{array}$ & Mean & Variance & minimum & maximum \\
\cline { 2 - 5 } & 36.50 & 16.089 & 15 & 91 \\
\hline
\end{tabular}

As the table above shows the average age of respondents is 36.05 . The variance is around 17 years with the youngest respondents ageing 15 and the oldest 91 years. Regarding the hypothesis of the effect of socioeconomic status on mental disorder, the independent test result was 180.128 which clearly suggest a strong relation between socioeconomic statuses on the one hand and the prevalence of mental disorder on the other. This means that people with a mental disorder were mainly from the lower classes of society and those without disorders mainly from the privileged class. Based on the linear regression model, the rise in social and economic class will decrease the prevalence of mental disorder by about 3.57 standard units. Regarding the effect of employment (employed/unemployed) on mental disorder the Chi-square independence test clearly showed that employment and mental disorder are related and the results are generalizable. In order to better understand the intensity of this relation, Cramer's V measure and the level of significance were 0.37 and 0.000 respectively which show a moderate relationship which is generalizable.

Table 3

\begin{tabular}{lll}
\hline The place of the individual in the family & Prevalence & Frequency \\
\hline Head of the family & 101 & 26.30 \\
Husband or wife & 50 & 13.02 \\
Girl or boy & 150 & 39.06 \\
Grandson or granddaughter & 20 & 5.21 \\
Parents & 8 & 2.08 \\
Brother or sister & 6 & 1.56 \\
Other relations & 20 & 5.20 \\
Not related & 25 & 6.51 \\
Total & 384 & 100 \\
\hline
\end{tabular}

This table includes the prevalence and frequency of place of the individual in the family. For example, 101 respondents $(26.30 \%)$ are heads of the family. 150 respondents $(39.06 \%)$ were boys or girls in the family as well.

Table 4

\begin{tabular}{lll}
\hline Head of the family's income & Prevalence & Frequency \\
\hline Less than 4 million dongs & 18 & 4.68 \\
4 to 10 million Dongs & 34 & 8.85 \\
10 to 15 million Dongs & 196 & 51.04 \\
15 to 20 Dongs & 134 & 34.89 \\
20 to 25 million Dongs & 3 & 0.78 \\
Total & 384 & 100 \\
\hline
\end{tabular}

According to the respondents, in $4.68 \%$ of the cases (18 respondents) heads of the family earn less than 4 million Dongs (each US dollar is approximately 22000 dongs). 34 respondents (8.85\%) reported an income of 4 to 10 million Dongs and 196 of them stated their income to be 10 to 15 million Dongs. Therefore, the number of respondents with a total income of 10 to 15 million Dongs per month is more than other income groups. The second spot is for those with a monthly income of 15 to 20 million Dongs. 
Table 5

\begin{tabular}{lll}
\hline Family status & Prevalence & Frequency \\
\hline Married & 304 & 79.16 \\
Divorced & 1 & 0.26 \\
Single & 79 & 20.57 \\
Total & 384 & 100 \\
\hline
\end{tabular}

Regarding the family status of the respondents, the data gathered shows that 304 of them (79.16\%) are married. This group has the highest numbers then come the single group with 79 members $(20.57 \%)$. Finally, only one of the respondents reported being divorced-which makes up $0.26 \%$ of the respondents.

Table 6

\begin{tabular}{lll}
\hline Domicile & Prevalence & Frequency \\
\hline City & 130 & 33.85 \\
Slum dog & 14 & 3.64 \\
Suburbs & 240 & 62.5 \\
Total & 384 & 100 \\
\hline
\end{tabular}

Of the total number of 384 respondents, $62.5 \%$ or 240 people reported their domicile to be in the suburbs. The highest number was for this group. Next, the city dwellers make up 33.85\% or 130 respondents. 14 people reported that they live in slums.

Table 7

\begin{tabular}{lllll} 
Descriptive statistics of & Mean & Variance & minimum & maximum \\
\cline { 2 - 5 } respondents' family size & 4.36 & 2.210 & 1 & 20 \\
\hline
\end{tabular}

The respondents' family size was 4.63. The variance of this answer was 2.012 individuals. The smallest family was 1 individual and the largest was 20. The Cramer's V measure with the significance level below 0.005 was 0.342 . This suggests a strong positive relation between the two variables; namely having a second job increases the probability of mental disorders to 0.342 . Regarding the effect of ethnicity on mental disorder, the Chi-square independent test showed that ethnicity and the prevalence of mental disorder are not strictly related.

Table 8

\begin{tabular}{lll}
\hline Housing status & Prevalence & Frequency \\
\hline House owner & 320 & 83.33 \\
Tenant & 61 & 15.88 \\
Governmental & 1 & 0.26 \\
Undeclared & 2 & 0.52 \\
Total & 384 & 100 \\
\hline
\end{tabular}

320 respondents or nearly $83 \%$ reported being house owners. The highest number was for this group. 61 respondents or $15.88 \%$ were living in rented domiciles. Only 1 individual was living in governmental houses and 2 respondents did not report their housing status.

Table 9

\begin{tabular}{rrr}
\hline Ethnicity & Prevalence & Frequency \\
\hline Kinh & 337 & 87.8 \\
Khme & 17 & 4.4 \\
Chinese overseas & 22 & 5.7 \\
Missing & 8 & 2.1 \\
Total & 384 & 100 \\
\hline
\end{tabular}


The majority of respondents, 337, nearly 88\%, reported their ethnicity to be Kinh. 22 respondents were Chinese overseas and 17 were Khmer.

Table 10

\begin{tabular}{lll}
\hline Religion & Prevalence & Frequency \\
\hline Buddhist & 180 & 46.87 \\
Christian & 35 & 9.11 \\
Atheist & 160 & 41.66 \\
Other religions & 4 & 1.04 \\
Undeclared & 5 & 1.3 \\
Total & 384 & 100 \\
\hline
\end{tabular}

180 respondents identified themselves as Buddhists (46.87\%), 35 respondents reported themselves as Christians (9.11\%) and 160 respondents were atheists (41.66\%). The results show that the majority of the respondents were Buddhists. The checking of research hypotheses implies a meaningful effect of the sociological factors on mental health. Regarding the effect of migration on the prevalence of mental disorder the Chi-square shows 26.381 which means this factor is related to mental disorder. The Pearson's correlation coefficient was -0.26 which proves the longer an individual life in his/her neighborhood, the less he/she may suffer from mental disorders. Regarding the effect of education on mental disorder the Chi-square test result was 12.388 which suggest a significant relationship between these dependent and independent variables. Regarding the effect of the second job on mental disorder, the Chi-square independent test clearly showed that the second job and mental disorders are highly connected. In order to better understand the intensity of this relation the Cramer's V measure was used. This being said, the relation is generalizable. The effect of gender on the prevalence of mental disorder was studied by regression and the results showed that being female increases the probability of mental disorder by 1.1 times.

Linear regression also showed that being female increases the chance of mental disorder by $0.39 \%$. Chisquare independence test statistics was 47.262 which suggest that there is a significant relationship between social strain and the prevalence of mental disorder. The results of the logistic regression and the odds ratio (6.25) and the 95\% confidence interval show that the prevalence of mental disorder as a dependent quantity and the social strain as an independent quantity is directly and positively related. This means that social strain increases the prevalence of mental disorder by 6.26 regression units. Using the linear regression model showed that social strain increases the prevalence of mental disorder by about 13.5 standard units the effect of a decrease in sympathy and social trust on mental disorder was evaluated by different statistical tests and the results showed that this variable and mental disorder are directly connected. The results of the correlation test (r) suggested that sympathy and social trust and mental disorder have a strong and diverse connection which is completely significant. Increase in support, sympathy, and social trust will result in a decrease in mental disorders. The effect of statistical tests regarding social capital proved its strong effect on the mental disorder. The results of the correlation test (r) suggested that sympathy and social trust and mental disorder have a strong and negative connection which is completely significant.

The increase in social capital will result in a decrease in mental disorder. The relationship between these two variables is seen to be strong. Regarding the effect of religiosity on mental disorder using linear regression it was demonstrated that this sociological parameter has no significant correlation with a mental disorder in this population.

$y_{\text {General Health Status }}=\frac{33}{615}-\frac{4}{191 x_{\text {Religional Activities }}}$

As a result, there is no strict relation between religiosity and high prevalence of mental disorder. The resulting regression model showed that a positive answer to religiosity would decrease the prevalence of mental disorder by about 4 units (negative correlation regression). Therefore, it can be said that there was no significant statistical relation between suffering from mental disorders and religiosity among the respondents of this research. 


\section{Discussion and Conclusion}

The present study shows that social factors which affect the prevalence of mental disorders include migration, family status, socioeconomic status, employment, social strains, and social capital. It may be asked how these factors can be accommodated within the Durkheim Ian and Mertonian approaches. As we indicated before, according to Durkheim, in modern societies where social division of labor developed, the traditional moral discipline which justifies the social inequalities is weakened, and a kind of anomie is dominant, the migration of individuals from different places with different cultures and limitless desires unfulfilled will lead them to permanent feelings of deprivation, discrimination and frustration which will result in social and mental collapse. Our data showed the effect of migration on the mental disorder is significant in HCMC, though regarding the high level of employment there and its extended division of labor, its share in the prevalence of mental disorders is expected to be much less than other areas with the higher unemployment rate and simpler division of labor. Durkheim believed that corporations and employment groups can create social cohesion in modern times. Regarding the social strains and the effect of macro and me so economic structural factors on mental health the Mertonian analysis was enlightening here.

When the system blocks the ways to fulfil the desires as a result the individual will face stress, mental pressure, loss of self-esteem, etc. The continuity of such situation results in mental collapse. This situation holds true, although on a smaller scale, for HCMC. Social strain increased the chances of mental disorder. Another social parameter that its malfunction can be traced in the Mertonian anomic situation is the social capital. Our study in HCMC showed that the majority of individuals who suffered from mental disorders had low social capital. Under the multilayer question of social capital our respondents had confirmed these items; social trust, interracial trust, civic collaborations, associational involvements, giving and volunteering, and faith-based engagements. In order to shed more light on this matter, in addition to the previously pictured conditions about anomie and economic and social fluctuations, we should consider integrity too. One of the characteristics of the mental disorder, especially in the time of depression, is the individual's desire for unsociability and isolation. The results of our research confirmed this and showed that individuals with a mental disorder were more isolated and had the lower rate of social capital compared to mentally healthy individuals. The last sociological factor that was expected to be effective on mental disorder was religiosity. As it was indicated before, a mental disorder in HCMC was not related to this independent variable.

But how this can be explained sociologically? As it was discussed before, in modern societies other social formations may replace the religious uniting and justificatory functions. In HCMC, the meagre unemployment rate, secularism, relative general satisfaction, strong family bondage, tolerant mentality and culture, and ideological passivity have worked to substitute the supporting role of religiosity. They have replaced the positive role that religion plays to facilitate mental health in many religious communities. To sum up, in Vietnam, HCMC in particular, the following positive conditions which were relatively acceptable, helped to decrease the prevalence of mental disorders: high employment, provision of basic economic needs, high literacy rate, low rate of socio-ethnic tensions, invisibility of security approaches in the city, a more popularity administration, a more public services and mass facilities, an extensive welfare services even if at times are minimal in quality, a relatively high social trust, very strong family ties, a good social support atmosphere, calm morality and behaviour which is sometimes passive, low rates of tension and violence, religious and ideological tolerance, the culture of contentment and acceptance of the current situation, general hope for a better future, the widespread spirit for work.

Development along with low expectations cooperation and mutual respect, a strong sense of nationalism and national pride etc. the sociological data extracted from our research, as well as the local participative observations we had, support the presence of the features and characteristics we assessed above. However, these are interesting and instructive realities because the above-mentioned characters, attitudes, mentalities, and conducts are present in a city and in a country which survived a devastating war with the USA only a few decades ago and which was left only with the destruction of their economic, productive, environmental and natural foundations, along with horrible human disasters. Without those Vietnamese features, mental disorder there now should be more than the global normal situation, and not less as it is in fact. To end up, we have some suggestions for the policy-makers in Vietnam; to lower down the mental disorders it would be effective to keep unemployment low especially in smaller towns and rural areas, to facilitate social capital 
enhancement measures, to promote social services quantitatively and qualitatively, especially in more deprived areas. And the last; more comprehensive and specific research are needed to be carried out in different regions and localities to help a better review and reform of mental health policy and action.

Acknowledgment: We are grateful to TDT university students of sociology who did the works of questionnaires distribution and collection: Hoang Trong Ngoc, Nguyen Phi Hien, Nang Thi My Duyen, Nguyen Minh Hieu, Nguyen Thi Phuong Thao, Hua Kim Huong, Ho Minh Thong, Ly Phuong Quynh, and their coordinator; TrieuThuy Mi.

\section{References}

ADB (Asian Development Bank). (2018). Asian Development Outlook. Manila: ADB.

Allen, J., Balfour, R., Bell, R., Marmot, M. (2014). Social Determinants of Mental Health, International Review of Psychiatry, 26(4), 392-407.

Aneshensel, C. S., Phelan, J. C., Bierman, A. (2012). Handbook of the Sociology of Mental Health. Netherlands: Springer Publication.

Aseltine, J. R. R. H., Gore, S., Gordon, J. (2000). Life Stress, Anger and Anxiety, and Delinquency: An Empirical Test of General Strain Theory, Journal of Health and Social Behavior, 41(3), 256-275.

Bessa, Yawo. (2012). Modernity Theories and Mental Illness: A Comparative Study of Selected Sociological Theories. International Journal of Humanities and Social Science, 2, 31-38.

Carod-Artal, F. J. (2017). Social Determinants of Mental Health", Global Mental Health,

Cockerham, W. C. (2017). Sociology of Mental Disorders $10^{\text {th }}$ Ed. London and New York: Rutledge Publication.

Das, J., Friedman, J., McKenzie, D., Do, Q. T. (2009). Mental Health Patterns and Consequences: Results from survey data in five developing countries, Journal of Development Economics, 23(1), 31-55.

Durkheim, E. (1951 [1897]). Suicide: A Study in Sociology. Translated by Spaulding John A.; Simpson, G. 1st ed. New York: The Free Press of Glencoe.

Fryers, T. (2003). Social inequalities and the common mental disorders, Social Psychiatry and Psychiatric Epidemiology, 38(5), 229-237.

Giddens, A. (1997). Durkheim. GB: Fontana Press.

Huy, N.V., Dunne, M. P., Debattista, J. (2015). Factors Associated with Depression Among Male Casual Laborers in Urban Vietnam, Community Mental Health Journal, 51(5), 575-584.

Kugelmass, H., Garcia, A. (2015). Mental Disorder among Nonreligious Adolescents, Mental Health Religion Cult, 18, 368-379.

Lee, K., Zapelli, R., Goldner, E. M., Cong V. N., Corbett, K. K., Murphy, J. (2015). The Political Economy of Mental Health in Vietnam: Key Lessons for Countries in Transition. Asia and the Pacific Policy Studies, 2(2), 266-279.

Merton, R. K. (1968). Social Theory and Social Structure. New York: The Free Press.

Merton, R. K. (1938). Social Structure and Anomie, American Sociological Review, 3, 672-82.

Merton, R. K. (1995). Opportunity Structure, in the Legacy of Anomie Theory, NJ, Transaction Publishers.

Nguyen, H. V., Ha Thi, H. D., Van Thi, A. L., Ngoc-Anh, M. (2018). Reviewing the Latest National Policies and Services for People with Severe Mental Health Disorders in Government-funded Institutions in Vietnam, and Policy Recommendations for Service Improvements, Asia Pacific Journal of Social Work and Development, 28(1), 56-68.

Nguyen, H. (2015). Linking Social Work with Buddhist Temples: Developing a Model of Mental Health Service Delivery and Treatment in Vietnam. British Journal of Social Work, 45(4), 1242-1258.

Richardson, L. K., Amstadter, A. B., Kilpatrick, D. G., Gaboury, M. T., Trinh Luong, T., Lam Tu, T., Nguyen Thanh, T., Tran, T., La Thi, B., Tran Thu, H. (2010). Estimating Mental Distress in Vietnam: The Use of the SRQ-20. International Journal of Social Psychiatry, 56, 133-142.

Sederer, L. I. (2016). The Social Determinants of Mental Health, Psychiatric Services, 67, 234-235.

Shim, R. \& Compton, M. (2018). Social Determinants of Mental Health, Addressing the Social Determinants of Mental Health.

Silva, M., Loureiro, A., Cardoso, G. (2016). Social Determinants of Mental Health: A review of the evidence, European Journal of Psychiatry, 30(4), 259-292. 


\section{Journal of Social and Development Sciences (ISSN 2221-1152)}

Vol. 9, No. 4, pp. 1-13, December 2018

Singhal, S. (2018). Early Life Shocks and Mental Health: The long-term effect of war in Vietnam, Journal of Development Economics.

Tavakol, M., Armstrong, D. (2013). Medical Sociology. $3^{\text {rd }}$ Ed. Tehran: Shahid Beheshti University Publication, [Persian].

VnExpress. (2016). People with Mental Illness Left Behind in Vietnam.

Vuong, D. A., Van Ginneken, E., Morris, J., Ha, S. T., Busse, R. (2011). Mental Health in Vietnam: Burden of Disease and Availability of Services, Asian Journal of Psychiatry, 4(1), 65-70.

Wibbelink, C. J. M., Machteld, H., Stams, G. J. M., Oort, F. J. A. (2017). Meta-analysis of the Association between Mental Disorders and Juvenile Recidivism. Aggression and Violent Behavior, 33, 78-90.

World Health Report. (2001). World Health Organization Website.

WHO. (2018). Constitution. 